\title{
Assessment of the Hepatic Veins in Poor Contrast Conditions using Dual Energy CT: Evaluation of a Novel Monoenergetic Extrapolation Software Algorithm
}

\section{Beurteilung von Lebervenen bei schwachen Kontrastbedingung in der Dual-Energy-CT: Evaluation eines neuartigen mono- energetischen Extrapolationsalgorithmus}

Authors

Affiliations
C. Schabel' ${ }^{1}$, M. Bongers' ${ }^{1}$, M. Sedlmair ${ }^{2}$, A. Korn ${ }^{3}$, U. Grosse' ${ }^{1}$, S. Mangold ${ }^{1}$, C. D. Claussen ${ }^{1}$, C. Thomas ${ }^{1}$

Department of Diagnostic and Interventional Radiology, University Hospital of Tuebingen

Healthcare, Siemens AG, Forchheim

Department of Diagnostic and Interventional Neuroradiology, University Hospital of Tuebingen
Key words

- CT

- monoenergetic

- liver

- contrast

- dual energy

post-processing

received 20.12.2013

accepted 21.3.2014

\section{Bibliography}

DOI http://dx.doi.org/ $10.1055 / \mathrm{s}-0034-1366423$

Published online: 22.4 .2014

Fortschr Röntgenstr 2014; 186:

591-597 @ Georg Thieme

Verlag KG Stuttgart · New York ISSN 1438-9029

\section{Correspondence \\ Dr. Malte Bongers}

Department of Diagnostic and Interventional Radiology, University Hospital of Tuebingen Hoppe-Seyler-Straße 3

72076 Tübingen

Germany

Tel.: ++49/7071/2982087

Fax: ++ 49/70 71/295845

malte.bongers@med.uni-

tuebingen.de

License terms

\section{Zusammenfassung}

$\nabla$

Zielsetzung: Die Evaluierung eines neuartigen monoenergetischen Nachverarbeitungsalgorithmus (MEI+) bei Patienten mit eingeschränkter intrahepatischer Kontrastierung.

Material und Methoden: 25 Patienten wurden retrospektiv in der Studie eingeschlossen. Computertomografien des oberen Abdomen in später Kontrastmittelphase, welche im Dual-Energy-Modus $(100 / 140 \mathrm{kV})$ akquiriert wurden, wurden als Modell für eine schwache intrahepatische Kontrastierung verwendet. Es wurden linear gewichtete Mischbilder (MI), traditionelle monoenergetische (MEI), reine 100 und $140 \mathrm{kV}$ sowie MEI+ Bilder berechnet. MEI+ ist eine neuartige Technik, welche frequenzbasiert rauschbehaftete virtuelle niedrigkeV Bilder mit Bildern optimaler keV (aus Perspektive des Bildrauschens) kombiniert und so die Vorteile beider Bilddatensätze vereint. Signal-zuRauschen (SNR) und Kontrast-zu-Rauschen (CNR) intrahepatischer Gefäße (IHV) und des Leberparenchyms (LP) wurden objektiv gemessen. Subjektiv wurde die Abgrenzbarkeit der IHV von zwei Untersuchern im Konsensus beurteilt und mit portal-venösen Bildern verglichen.

Ergebnisse: MEI+ verbesserte SNR von IHV (5,7 \pm $0,4$ bei $40 \mathrm{keV})$ und LP $(4,9 \pm 1,0$ bei $90 \mathrm{keV})$ sowie CNR $(2,1 \pm 0,6$ bei $40 \mathrm{keV})$ erheblich, verglichen mit MEI $(5,1 \pm 1,1$ bei $80 \mathrm{keV} ; 4,7 \pm 1,0$ bei $80 \mathrm{keV} ; 1,0 \pm$ $0,4$ bei $70 \mathrm{keV})$, MI (5,2 $\pm 1,1 \mathrm{M} 5: 5 ; 4,8 \pm 1,0 \mathrm{M} 5: 5$; $1,0 \pm 3,5 \mathrm{M} 9: 1)$, reinen $100 \mathrm{kV}$ Bildern $(4,4 \pm 1,0$; $3,7 \pm 0,8 ; 1,0 \pm 0,3)$ und $140 \mathrm{kV}$ Bildern $(2,8 \pm 0,5$; $3,1 \pm 0,6 ; 0,1 \pm 0,2)$. Die subjektive Beurteilung schätzte $\mathrm{MEI}+$ bei $40 \mathrm{keV}$ gegenüber allen anderen Bildern als überlegen ein.

Schlussfolgerung: MEI+ ist ein vielversprechender Algorithmus für die monoenergetische Extrapolation, welcher die Limitation eines hohen Bildrauschens bei niedriger virtueller $\mathrm{keV}$ überwindet

\section{Abstract \\ $\nabla$}

Purpose: To evaluate a novel monoenergetic postprocessing algorithm $(\mathrm{MEI}+)$ in patients with poor intrahepatic contrast enhancement.

Materials and Methods: 25 patients were retrospectively included in this study. Late-phase imaging of the upper abdomen, which was acquired in dual-energy mode $(100 / 140 \mathrm{kV})$, was used as a model for poor intrahepatic contrast enhancement. Traditional monoenergetic images (MEI), linearly weighted mixed images with different mixing ratios (MI), sole 100 and $140 \mathrm{kV}$ and MEI+ images were calculated. MEI+ is a novel technique which applies frequency-based mixing of the low $\mathrm{keV}$ images and an image of optimal keV from a noise perspective to combine the benefits of both image stacks. The signal-to-noise ratio (SNR) and contrast-to-noise ratio (CNR) of the intrahepatic vasculature (IHV) and liver parenchyma (LP) were objectively measured and depiction of IHV was subjectively rated and correlated with portal venous imaging by two readers in consensus.

Results: MEI+ was able to increase the SNR of the $\operatorname{IHV}(5.7 \pm 0.4$ at $40 \mathrm{keV})$ and $\mathrm{LP}(4.9 \pm 1.0$ at $90 \mathrm{keV})$ and CNR (2.1 \pm 0.6 at $40 \mathrm{keV})$ greatly compared to MEI $(5.1 \pm 1.1$ at $80 \mathrm{keV}, 4.7 \pm 1.0$ at $80 \mathrm{keV}, 1.0 \pm$ 0.4 at $70 \mathrm{keV})$, MI (5.2 $\pm 1.1 \mathrm{M} 5: 5,4.8 \pm 1.0 \mathrm{M} 5: 5$, $1.0 \pm 3.5 \mathrm{M} 9: 1)$, sole $100 \mathrm{kV}$ images $(4.4 \pm 1.0,3.7 \pm$ $0.8,1.0 \pm 0.3)$ and $140 \mathrm{kV}$ images $(2.8 \pm 0.5,3.1 \pm$ $0.6,0.1 \pm 0.2$ ). Subjective assessment rated MEI+ of virtual $40 \mathrm{keV}$ superior to all other images.

Conclusion: $\mathrm{MEI}+$ is a very promising algorithm for monoenergetic extrapolation which is able to overcome noise limitations associated with traditional monoenergetic techniques at low virtual $\mathrm{keV}$ levels and consequently does not suffer from a decline of SNR and CNR at low keV values. This algorithm allows an improvement of IHV depiction in the presence of poor contrast. 
und keine Abnahme von SNR und CNR bei niedrigen keV verursacht. MEI+ ermöglicht eine signifikante Verbesserung der IHVDarstellung bei eingeschränkter Kontrastbedingung.
Key points:

- The evaluated new image-based algorithm for virtual monoenergetic imaging allows calculating low virtual keV images from dual energy datasets with significantly improved contrast-to-noise ratios.

- The image based novel monoenergetic extrapolation algorithm applies frequency-based mixing of the low keV images and an image of optimal keV from a noise perspective to combine the benefits of both image stacks.

- When compared to traditional monoenergetic images, the novel monoenergetic algorithm has improved contrast-to-noise ratios for both low and high virtual keV images.

- Contrast-enhanced dual energy images with poor contrast conditions can be significantly improved, e.g. late phase imaging of the liver.

Citation Format:

- Schabel C, Bongers M, Sedlmair M et al. Assessment of the Hepatic Veins in Poor Contrast Conditions using Dual Energy CT: Evaluation of a Novel Monoenergetic Extrapolation Software Algorithm. Fortschr Röntgenstr 2014; 186: 591-597

\section{Introduction}

The reliable visualization of the hepatic vasculature is essential for liver imaging and pre-interventional planning but can be challenging with CT due to a variety of reasons. For example, in patients with acute or chronic liver disease and severely altered hemodynamics of the portal venous system, the timing of optimal contrast enhancement can be difficult $[1,2]$. Furthermore, renal dysfunction accompanied by the need for saving contrast media can result in poor portal venous contrast enhancement $[3,4]$, thus demanding optimization of examination protocols or improved post-processing capabilities.

Dual-energy CT (DECT) has recently been revived with the introduction of dual-source CT. The ability to simultaneously acquire two CT scans with different photon energies allows algorithmbased monoenergetic extrapolation [5], leading to virtual monoenergetic images (MEI) of selectable photon energies. Commercially available software allows the creation of MEI with virtual photon energies in a range of 40 to $190 \mathrm{keV}$. Due to a reduction of beam hardening artifacts, MEI with high virtual photon energies can be used to reduce metal artifacts [6 - 11]. In MEI with low virtual photon energies, the Hounsfield numbers of materials with a high atomic number like iodine and calcium are increased, leading to an improved iodine contrast [12-14]. However, since the image noise increases even more than the iodine contrast, the contrastto-noise ratio (CNR) of traditional MEI with very low virtual photon energies is lower than in the source CT images [15].

To obtain better results and to overcome noise limitations associated with traditional monoenergetic techniques [15], we investigated a novel technique (MEI+, Monoenergetic+, Siemens Healthcare, Forchheim, Germany) which applies a frequencybased mixing of the low keV images (which contain the high contrast signal) and an image of optimal keV from a noise perspective (typ. around $70 \mathrm{keV}$ ) to combine the benefits of both images stacks - the low noise and the improved contrast.

The aim of this study was to evaluate the potential of MEI and $\mathrm{MEI}+$ to increase iodine contrast for the visualization of liver vasculature in comparison to regular CT images. Since patients with severely altered hemodynamics of the portal venous system are infrequently seen in clinics, clinically indicated additional late- phase scans of the upper abdomen with poor depiction of intrahepatic vessels were chosen as a model for patients with intrinsically substandard hepatic image quality and more generally for situations requiring boosting of iodine-dependent contrast in order to achieve diagnostic image quality.

\section{Materials and Methods}

$\nabla$

This retrospective study was approved by the local ethics committee. In our institution, abdominal CT scans were frequently acquired in dual-energy mode since virtual non-contrast images can be calculated from these. Patients were scanned using a 2nd generation dual-source CT system (SOMATOM Definition Flash with a Stellar detector, Siemens Healthcare, Forchheim, Germany). The scanning parameters for abdominal DE scans at our institution were: collimation $2 \times 0.6 \times 64$ with pitch of 0.6 , tube voltages $100 / 140 \mathrm{kV}$ with tin-filter for $140 \mathrm{kV}$, reference effective tube currents 196/151 mAs. Depending on the patient's weight and kidney function, 90 to $120 \mathrm{ml}$ of contrast medium (400 mg Iomeprol/ml, Imeron 400, Bracco, Konstanz, Germany) and $40 \mathrm{ml}$ of saline chaser were injected through an antecubital vein catheter at a flow rate of about $2.2 \mathrm{ml} / \mathrm{s}$ using a dual-syringe injector (CT Stellant, Medrad, Indianola, Pennsylvania, USA). The most recent examinations with additional late-phase scans of the upper abdomen (typically indicated for the characterization of liver or kidney lesions) were reviewed. The latest 25 examinations with poor visualization of the intrahepatic vasculature (portal venous system and hepatic veins) were selected and included in this study. Using a software prototype (syngo.IPIPE 1.10.0.0, Siemens Healthcare), MEI and MEI+ were created at virtual photon energies of 40,50,60, 70, 80, 90, 100, 110, 120, 130, 150,170 and $190 \mathrm{keV}$. Furthermore, polychromatic mixed images (MI) composed of a linear combination of the scans of low $(100 \mathrm{kV})$ and high $(140 \mathrm{kV})$ energies with ratios of 1:9 (M0.1), 3:7 (M0.3), 5:5 (M0.5), 7:3 (M0.7) and 9:1 (M0.9) were created.

\section{Objective image evaluation}

All image series were imported into a custom MATLAB program, which enabled the propagation of identical region of interest 

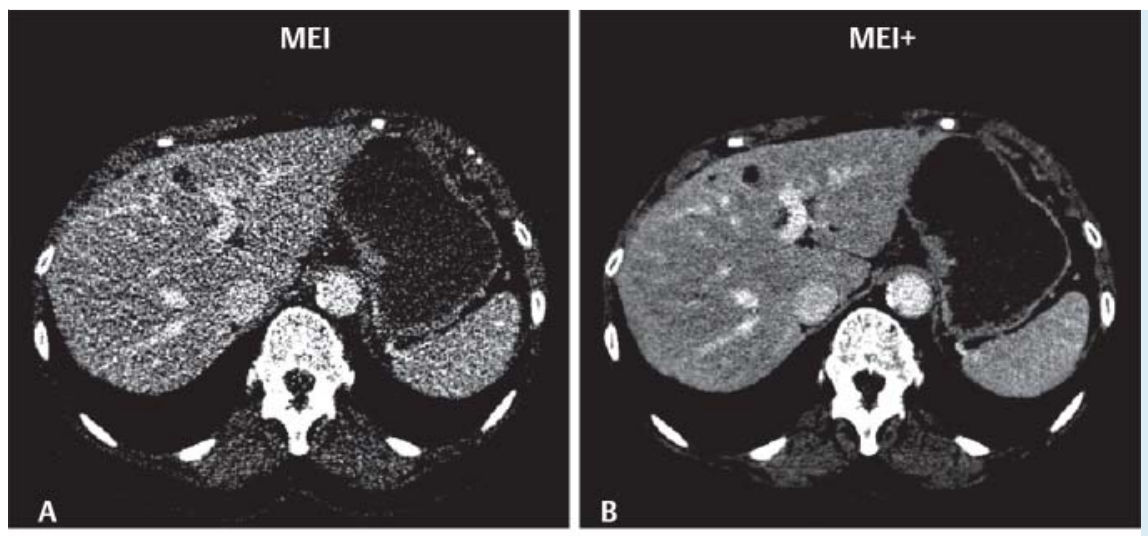

Fig. 1 The same image slice depicted as traditional monoenergetic (left column; A, C, E) and novel monoenergetic plus extrapolation (right column; B, D, F) at virtual $40 \mathrm{keV}$ (first row; A, B), $70 \mathrm{keV}$ (second row; C, D) and $190 \mathrm{keV}$ (third row; E, F). These images were used as reference images for the subjective assessment of datasets.

Abb. 1 Die gleiche Schichtposition dargestellt als traditionelle monoenergetische (linke Spalte; $A, C, E)$ und mit einer neuartigen monoenergetischen Extrapolationstechnik (rechte Spalte; B, D, F) bei virtuellen $40 \mathrm{keV}$ (erste Zeile; A, B), $70 \mathrm{keV}$

(zweite Zeile, C, D) und $190 \mathrm{keV}$ (dritte Zeile; E, F). Die hier dargestellten Bilder dienten weiterhin als
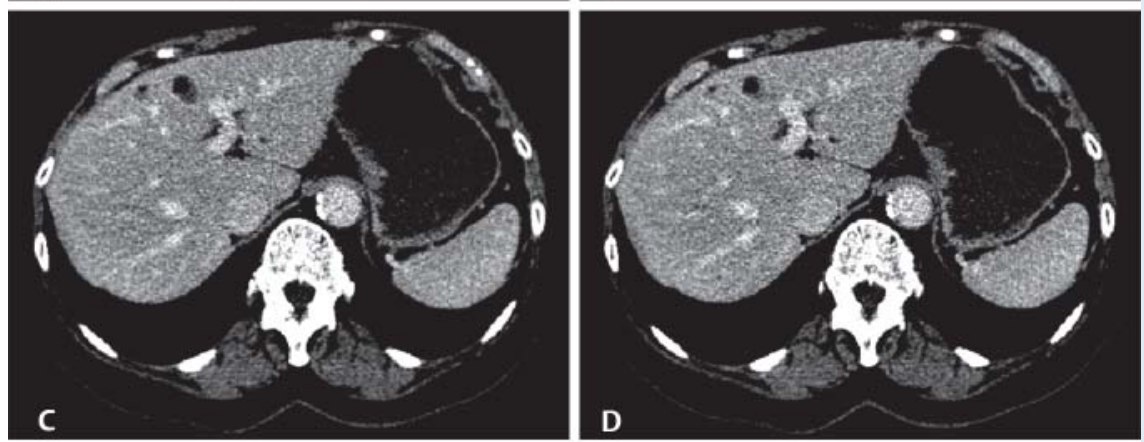
Referenzbilder für die subjektive Graduierung der Abgrenzbarkeit intrahepatischer Gefäße.
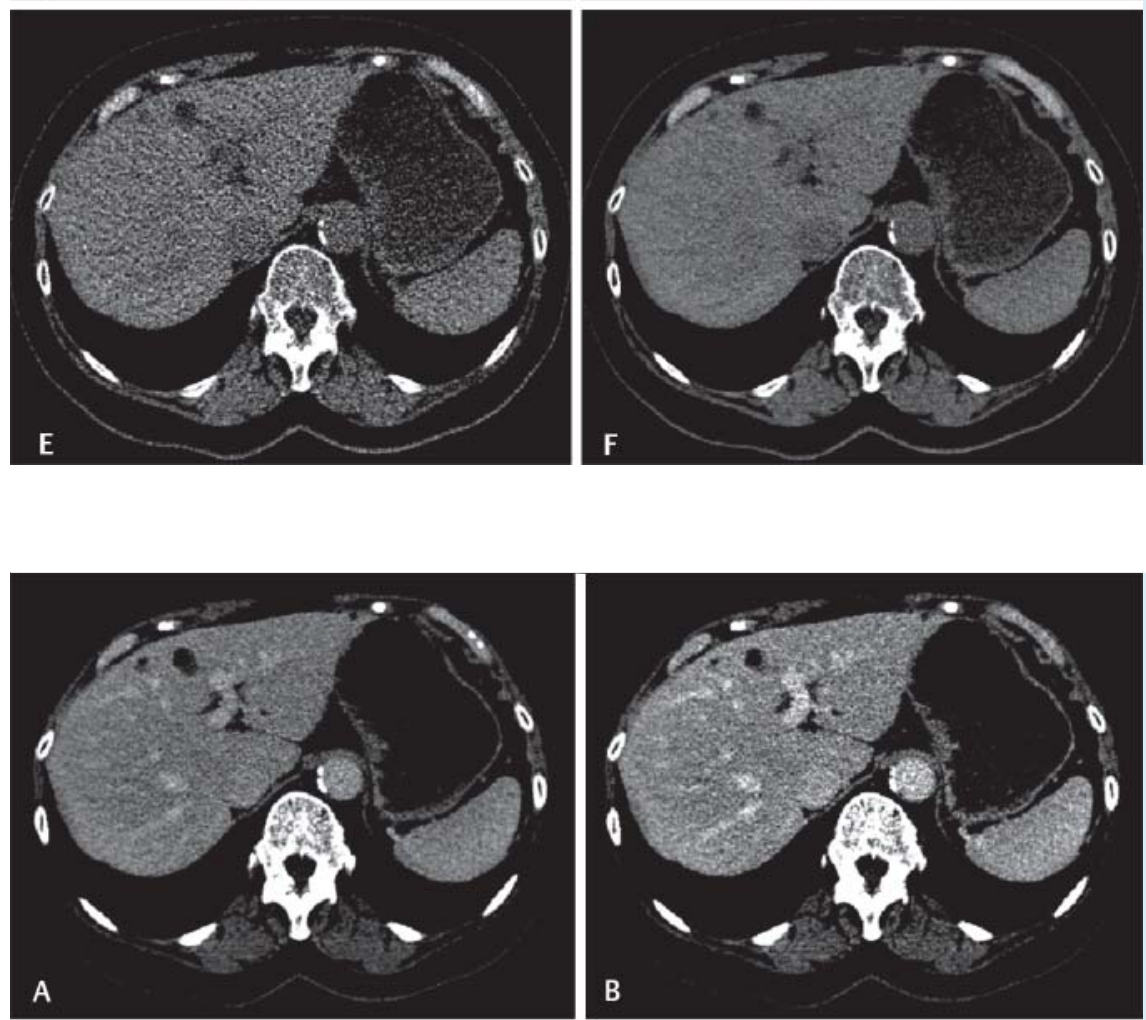

Fig. 2 The same image slice is depicted as linearweighted mixed images (linear combination of dual energy scans, A 5:5, B 7:3, C 9:1) and sole $100 \mathrm{kV}$ scan $\mathbf{D}$. Furthermore, these images were used as reference images for the subjective assessment of datasets.

Abb. 2 Die gleiche Schicht dargestellt als Mischbilder der DualEnergy Scans (A 5:5, B 7:3, C 9:1) und nur der $100 \mathrm{kV}$ Spirale (D 10:0). Die hier dargestellten Bilder dienten weiterhin als Referenzbilder für die subjektive Graduierung.
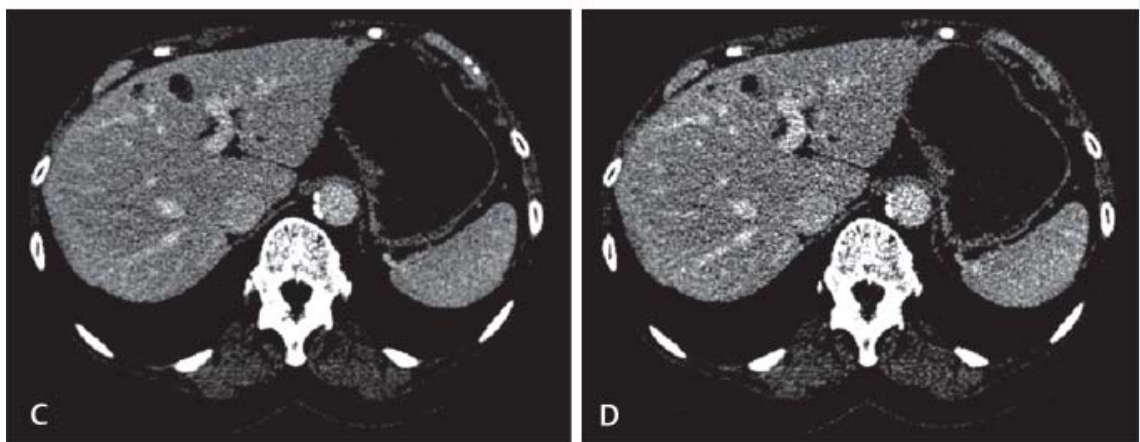
(ROI) measurements to multiple series. Multiple ROIs were defined within hepatic veins, portal veins and liver parenchyma using MEI+ of $40 \mathrm{keV}$. The mean CT numbers and image noise (pixel standard deviation) were recorded. Averaged signal-tonoise ratios (SNR) for intrahepatic vascular structures (IHV) and liver parenchyma (LP) as well as contrast-to-noise ratios (CNR) of the IHV and LP were calculated:

$\mathrm{SNR}=\mathrm{CT}$ numbers $/$ noise

$\mathrm{CNR}=\left(\mathrm{CT}\right.$ numbers ${ }_{\mathrm{IHV}}-\mathrm{CT}$ numbers $\left.{ }_{\mathrm{LP}}\right) /$ mean noise $^{1}$

\section{Subjective image evaluation}

According to the results of the objective CNR analysis, exemplary series of each patient (MEI/MEI+40/70/190 keV, M0.3, M0.5, M0.7, M0.9 and sole $100 \mathrm{kV}$ images) were reviewed by two readers in consensus. A subjective 5-point Likert scale was used to assess the depiction of IHV and the accordance with true portal-venous imaging (1: no visibility ( $\bullet$ Fig. 1E, F), 2: poor depiction ( $\bullet$ Fig. 1A), 3: moderate depiction ( $\bullet$ Fig. 2A, B), 4: good depiction ( $\triangle$ Fig. 1C, D; $\odot$ Fig. 2C, D), 5: very good depiction (॰ Fig. 1B)).

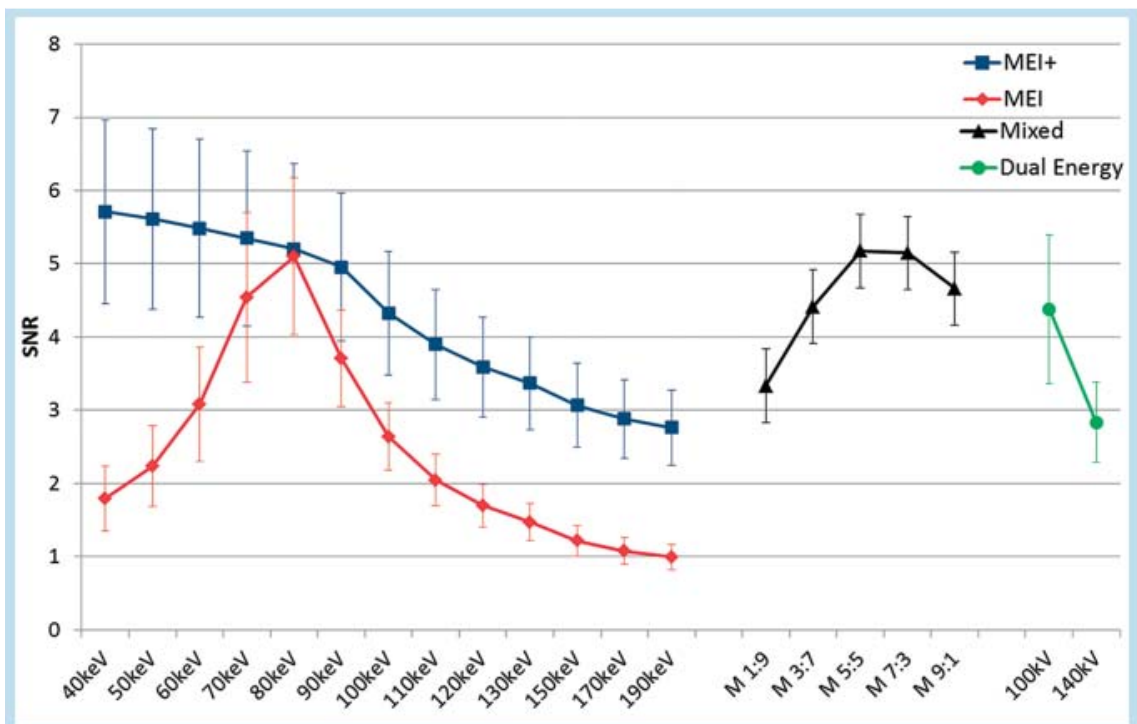

Fig. 3 Objective evaluation of signal-to-noise ratios (SNR) within intrahepatic vascular structures. The red line represents traditional monoenergetic extrapolation (MEI) with an SNR peak at $80 \mathrm{keV}$ due to strong propagation of noise at low virtual keV values. The blue line shows the novel monoenergetic plus extrapolation (MEI) with the best SNR at $40 \mathrm{keV}$. By way of comparison, polychromatic images based on linear-weighted mixing of dual energy scans (black line) and sole 100 and $140 \mathrm{kV}$ scans (green line) are shown.
Abb.3 Objektive Analyse der Signal-zu-Rausch-Quotienten (SNR) im Gefäßsystem der Leber. Die rote Linie stellt die Messungen in den traditionell monoenergetisch errechneten Bildern (MEI) dar mit einem globalen Maximum bei $80 \mathrm{kV}$, welches wegen der ausgeprägten Verstärkung des Rauschens bei niedrigen virtuellen keV Einstellungen zustande kommt. Die blaue Linie zeigt die neuartigen monoenergetischen Bilder (MEI+) mit dem besten SNR bei $40 \mathrm{keV}$. Zum Vergleich sind weiterhin die linear gewichtete polychromatischen Mischbilder der DualEnergy Scans (schwarze Linie) und die einzelnen 100/140 kV Scans (grüne Linie) dargestellt.

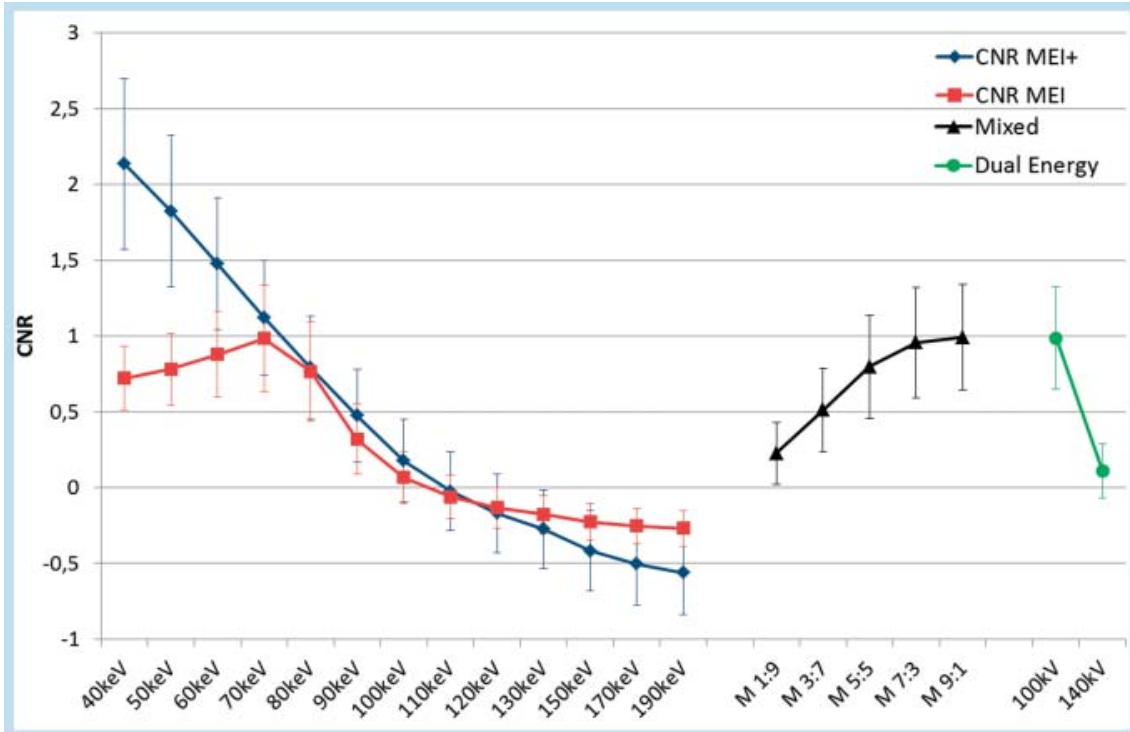

Fig. 4 Similar to $\bullet$ Fig. 3, except that contrast-tonoise ratios (CNR) of intrahepatic vasculature and liver parenchyma are presented. MEl: Monoenergetic extrapolated images: red line; MEI+: Novel MEI: blue line; MI: Linear-weighted mixed images (fraction 100/140 kV projections): black line; sole 100/140 kV scan: green line.

Abb.4 Ähnlich zu $\bullet$ Abb. 3 mit dem Unterschied dass das Kontrast-zu-Rausch-Verhalten von intrahepatischen Gefäßen und Leberparenchym dargestellt ist. MEl: monoenergetisch extrapolierte Bilder: rote Linie; MEI+: neuartiges MEI: blaue Linie; MI: linear gewichtete polychromatische Mischbilder (Verhältnis 100/140 kV Projektionen): schwarze Linie; nur 100/140 kV Scans: grüne Linie.

${ }^{1}$ mean noise $=\left(\right.$ noise $_{\mathrm{IHV}}+$ noise $\left._{\mathrm{LP}}\right) / 2$ 
Table 1 Objectively measured SNR and CNR values.

Tab. 1 Objektive Messung von SNR- und CNR-Werten.

\begin{tabular}{|lllll} 
& SNR of IHV & SNR of LP & CNR of IHV and LP & SNR of GB \\
\hline MEI+ & $2.8 \pm 0.5(190 \mathrm{keV})-5.7 \pm 1.3$ & $3.7 \pm 0.7(190 \mathrm{keV})-4.9 \pm 0.7$ & $-0.02 \pm 0.3(110 \mathrm{keV})-2.1 \pm 0.6$ & $0.7 \pm 0.4(40 \mathrm{keV})-1.1 \pm 0.5$ \\
& $(40 \mathrm{keV})$ & $(90 \mathrm{keV})$ & $(40 \mathrm{keV})$ & $(90 \mathrm{keV})$ \\
\hline MEI & $1.0 \pm 0.2(190 \mathrm{keV})-5.1 \pm 1.1$ & $1.2 \pm 0.3(40 \mathrm{keV})-4.7 \pm 1.0$ & $-0.06 \pm 0.1(110 \mathrm{keV})-1.0 \pm 0.4$ & $0.2 \pm 0.2(40 \mathrm{keV})-1.0 \pm 0.4$ \\
& $(80 \mathrm{keV})$ & $(80 \mathrm{keV})$ & $(70 \mathrm{keV})$ & $(80 \mathrm{keV})$ \\
\hline MI & $3.3 \pm 0.7(1: 9)-5.2 \pm 1.1(5: 5)$ & $3.5 \pm 0.7(1: 9)-4.8 \pm 1.0(5: 5)$ & $0.2 \pm 0.2(1: 9)-1.0 \pm 0.3(9: 1)$ & $0.8 \pm 0.4(1: 9)-1.0 \pm 0.4(5: 5)$ \\
\hline $100 \mathrm{kV}$ & $4.4 \pm 1.0$ & $3.7 \pm 0.8$ & $1.0 \pm 0.3$ & $0.7 \pm 0.3$ \\
\hline $140 \mathrm{kV}$ & $2.8 \pm 0.5$ & $3.1 \pm 0.6$ & $0.1 \pm 0.2$ & $0.7 \pm 0.3$ \\
\hline
\end{tabular}

SNR: Signal-to-noise ratio; CNR: Contrast-to-noise ratio; LP: Liver parenchyma; IHV: intrahepatic vasculature, GB: Gallbladder; MEl: Monoenergetic extrapolated images; $\mathrm{MEI}+$ : Novel MEI; MI: Linear-weighted mixed images (fraction $100 \mathrm{kV}: 140 \mathrm{kV}$ projections).

SNR: Signal-zu-Rausch-Verhältnis; CNR: Contrast-zu-Rausch-Verhältnis; LP: Leberparenchym; IHV: Inrahepatisches Gefäßsystem, GB: Gallenblase; MEl: Monoenergetisch extrapolierte Bilder; MEI+: neuartiges MEl; MI: Linear gewichtete Mischbilder (Anteil $100 \mathrm{kV}$ : $140 \mathrm{kV}$ Projektionen).

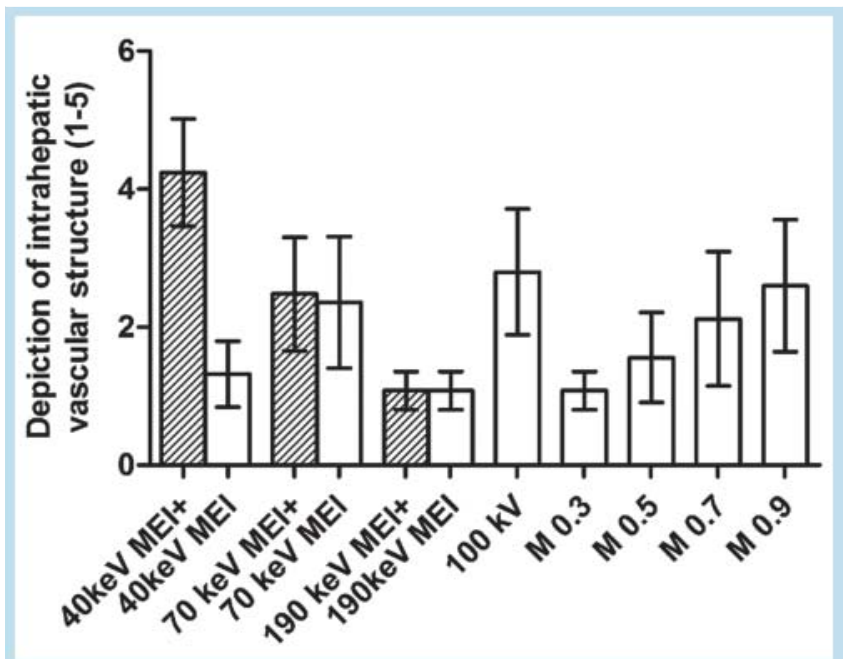

Fig. 5 Results of subjective image analysis are shown. Depiction of intrahepatic vasculature (IHV) was rated on a 5-point Likert scale with five being the highest rating. MEI+ provided the best depiction of the IHV due to increased iodine-dependent CT numbers and only a moderate increase in image noise. Sole $100 \mathrm{kV}$ projections proved to depict the IHV not significantly differently than MEI/MEI+ at $70 \mathrm{keV}$ or linearly mixed images (M0.3-0.9 (ratio 100/140 kV scan)).

Abb.5 Ergebnisse der subjektiven Bildanalyse. Die Darstellung der intrahepatischen Gefäße (IHV) wurde auf einer 5-Punkte Likert-Skala bewertet mit fünf als bestem Wert. MEI+ zeigte die beste Abgrenzbarkeit von IHV als Folge der erhöhten iodbasierten Schwächung und nur milden Zunahme des Rauschens. Bilder, die nur auf den Projektionen der $100 \mathrm{kV}$ Spirale (100 kV) basierten, zeigten keine signifikanten Unterschiede zu MEI/MEI+ bei $70 \mathrm{keV}$ oder zu linear gewichteten gemischten Bildern (M0.3 - 0.9 [Verhältnis 100/140 kV Spirale]).

\section{Statistical evaluation}

Statistical analysis was performed with Prism 5 (GraphPad, La Jolla, USA). Measurements were treated as paired samples and statistically compared using Wilcoxon matched pair tests for ordinal and paired t-tests for continuous data. P-values $<0.05$ were regarded as significant.

\section{Results}

25 patients (14 females, 11 males, age $62.9 \pm 16.2$ years) were included in this study. The reviewed late-phase scans were started
$193.6 \pm 44.8 \mathrm{~s}$ after beginning the application of contrast media $(93.6 \pm 11.1 \mathrm{ml})$. The mean CTDI recorded was $10.47 \pm 3.00 \mathrm{mGy}$. Objective image analysis revealed that MEI+ showed the best SNR values for both vascular structures $(5.7 \pm 1.3 \mathrm{at} 40 \mathrm{keV})$ and liver parenchyma ( $4.9 \pm 0.7$ at $80 \mathrm{keV}$ ) compared to MEI (IHV $5.1 \pm 1.1$ at $70 \mathrm{keV}$ and LP $4.7 \pm 1.0$ at $80 \mathrm{keV}$ ), MI (IHV $5.2 \pm 1.1$ and LP $4.8 \pm 1.0$ both for M0.5) and sole $100 / 140 \mathrm{kV}$ scans (IHV $4.4 \pm 1.0$ and LP $3.7 \pm 0.8$ both at $100 \mathrm{kV}$ ). MEI datasets showed optimal SNR values at $80 \mathrm{keV}$, while the SNR values decreased for low and high virtual $\mathrm{keV}$ values due to a strong increase in image noise. In contrast, enhanced attenuation of iodine outweighed the increase in image noise in MEI+ resulting in increased SNR values even in poorly contrasted liver veins ( $\bullet$ Fig. 3). Nevertheless, the best objective measure for the depiction of vascular structures within liver parenchyma was CNR that was found to be superior in MEI+ at $40 \mathrm{keV}$ (2.1 \pm 0.6$)$ by a more than 2-fold increase compared to MI (CNR $1.0 \pm 0.3 \mathrm{MO} .9)$, MEI $(1.0 \pm 0.4$ at $70 \mathrm{keV})$ and sole $100 \mathrm{kV}$ images $(1.0 \pm 0.3)$ ( $\bullet$ Fig. 4). Both MEI and MEI+ showed an inverse contrast for virtual keV settings above $110 \mathrm{keV}$, while MEI+ images showed a significantly higher absolute CNR (MEI+ CNR $-0.6 \pm 0.3$ vs. MEI $-0.2 \pm 0.1$ ). Compared to polychromatic images of linearweighted mixing of dual energy scans, MEI and MEI+ yielded few benefits at keV settings close to routine tube potential. However, the more the $\mathrm{keV}$ differed from the routine tube potential $(120 \mathrm{kV})$, the better MEI+ performed (MEI+ at $40 \mathrm{keV})$. MEI could not show an objective benefit compared to MI, since the best CNR was measured at $70 \mathrm{keV}$ and decreased significantly at low and high keV compared to MEI+, MIO.9 and sole $100 \mathrm{kV}$ scans.

In the absence of iodine contrast media, exemplarily assessed within the gallbladder, MEI+ showed similar SNR values $(1.1 \pm 0.5$ at $90 \mathrm{keV})$ like MI $(1.0 \pm 0.4 \mathrm{M} 0.5)$ and MEI $(0.8 \pm 0.4$ at $80 \mathrm{keV}$ ) but again less of an increase in image noise than MEI for low and high virtual $\mathrm{keV}$ values ( $\boldsymbol{\bullet}$ Table $\mathbf{1}$ ).

The subjective image assessment rated MEI+ images at $40 \mathrm{keV}$ best compared to all other evaluated series (MEI 40/70/190 keV, MEI+ 70/190 keV, M0.3, M0.5, M0.7, M0.9 and sole $100 \mathrm{kV}$ images) $(\mathrm{p}<0.0001)$. MEI images were rated highest at $70 \mathrm{keV}$ and did not show significant differences to MEI+ datasets $(p=0.15)$, which was consistent with our objective image analysis. Furthermore, MEI did not show significant improvement of the depiction of intrahepatic vessels $(\mathrm{p}=0.07)$ compared to images only reconstructed from $100 \mathrm{kV}$ projections. MEI at $40 \mathrm{keV}$, MEI/MEI+ at 190 $\mathrm{keV}$, MI (M0.3) and sole $140 \mathrm{kV}$ scan were rated not diagnostic in terms of intrahepatic vessel depiction (• Fig.5) 

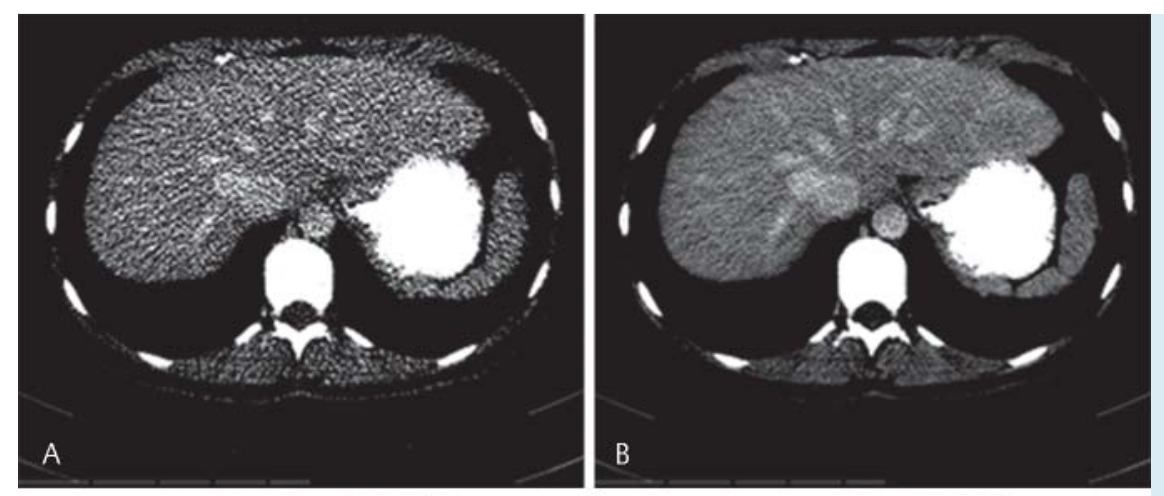

Fig. 6 Example of patient with poor image contrast. The same image slice depicted as traditional monoenergetic extrapolation at virtual $40 \mathrm{keV} \mathrm{A}$, novel monoenergetic plus extrapolation at virtual $40 \mathrm{keV}$ B, sole $100 \mathrm{kV}$ scan C and linear-weighted mixed image 5:5 $\mathbf{D}$.

Abb. 6 Beispiel eines Patienten mit eingeschränktem Bildkontrast. Die gleiche Schichtposition ist dargestellt als traditionelle monoenergetische Extrapolation $\mathbf{A}$, als neuartige monoenergetische $\mathrm{Ex}$ trapolation B, als $100 \mathrm{kV}$ Scan C und als linear gewichtetes Mischbild 5:5 D.
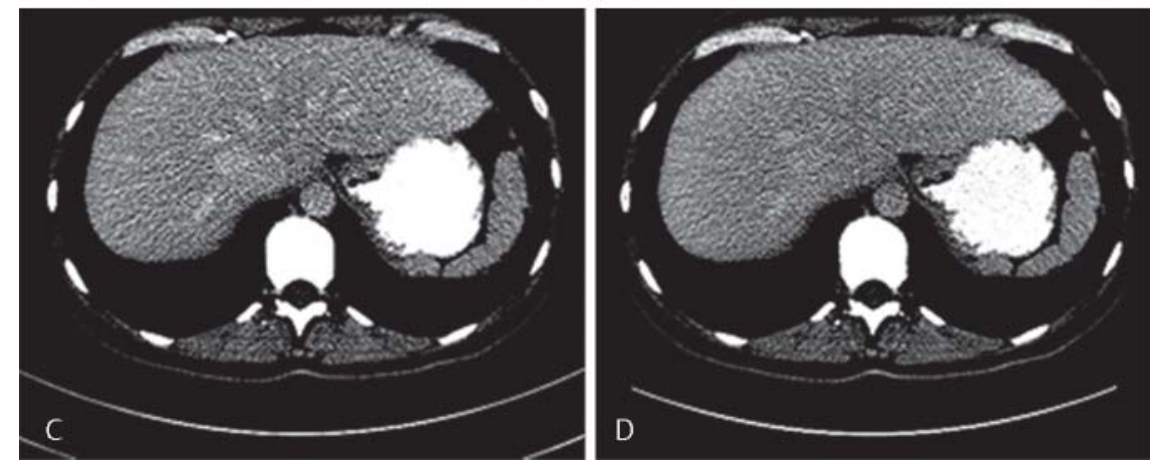

\section{Discussion \\ $\nabla$}

To the best of our knowledge, this is the first study evaluating the novel MEI+ algorithm, which facilitates frequency-based mixing of low keV images (which contain the high contrast signal) and an image of optimal keV from a noise perspective (typ. round $70 \mathrm{keV}$ ) to combine the benefits of both images stacks - the low noise and the improved contrast.

25 patients who had undergone a clinically indicated dual energy late-phase scan of the upper abdomen were retrospectively included in this study. MEI, MEI+, linearly weighted mixed images (MI) and sole 100/140 kV images were calculated in order to assess the depiction of intrahepatic vessels objectively and subjectively. Objective analysis of MEI showed the best SNR values in the intrahepatic vasculature (IHV) and liver parenchyma (LP) at virtual $80 \mathrm{keV}$ images, which was consistent with previous studies $[5,15]$. Nevertheless these images suffered from a predominant increase in image noise at low virtual keV values overcoming iodine's increased attenuation and consequently causing a decline of the SNR that was also consistent with previous findings $[5,15]$. In contrast, the novel MEI+ only suffered a mild increase of image noise at $<70 \mathrm{keV}$ and thus a significantly increased SNR compared to MEI, MI and sole 100 and $140 \mathrm{kV}$ scans. The CNR of the IHV and LP as an objective measure for the depiction of vessels within the liver showed a more than 2-fold increase of CNR values at virtual $40 \mathrm{keV}$. Subjectively, MEI+ at 40 $\mathrm{keV}$ was rated as the best way to depict intrahepatic vessels while having just a mild increase of noise levels and showed good accordance with portal venous phase imaging ( $\boldsymbol{0}$ Fig. $\mathbf{6})$.

Previous studies showed that liver imaging was able to benefit by monochromatic extrapolation of CT images $[16,17]$ in terms of increased sensitivity for the detection of lesions and greater diagnostic confidence [17]. Nevertheless, $70 \mathrm{keV}$ was recommended due to increased noise levels to achieve the best overall image quality $[15,17]$. MEI+ was able to overcome this limitation by still providing only mild image noise at $40 \mathrm{keV}$. Therefore, MEI+ images at $40 \mathrm{keV}$ could be regarded as ideal for the depiction of intrahepatic vessels [17]. Furthermore, this algorithm-based post-processing is a promising candidate for calculated saving of contrast media, from which patients with reduced kidney function might benefit $[3,4,18,19]$. These improved post-processing capabilities at low virtual keV values might also increase the sensitivity for the detection of soft-tissue lesions, e. g. in melanoma. Reduced contrast media CT angiographies might also be feasible, which should be evaluated in further studies.

One limitation of this study was its retrospective design. Latephase imaging of the upper abdomen was used as a model for the low contrast situation or missed portal venous phase. Nevertheless, patients had received the appropriate weight-adjusted amount of contrast media, which redistributed to tissues and started to be renally eliminated at the time of the late-phase examination. Furthermore, our patients did not have severe impairment of portosystemic blood flow and intrahepatic lesions were not assessed. The assumption that the sensitivity for the detection of intrahepatic lesions would improve was based on the hypothesis that a further increase of iodine-based contrast enhancement with just a mild increase in image noise would improve sensitivity, which was described as beneficial before [17]. A true limitation of any monoenergetic extrapolation is a possible amplification of beam hardening artifacts which was not evaluated in our study, but might cause problems with metal implants in patients, e. g. following back surgery.

In conclusion, MEI+ is a very promising algorithm for monoenergetic extrapolation, which is able to overcome noise limitations associated with traditional monoenergetic techniques at low virtual keV levels $[5,13,15]$. This algorithm allows an improvement of IHV depiction in the presence of poor contrast. 


\section{Acknowledgement}

The authors dedicate this article to Prof. Dr. Claus D. Claussen in occasion of his retirement.

\section{References}

1 Vignaux $\mathrm{O}$, Gouya H, Augui J et al. Hepatofugal portal flow in advanced liver cirrhosis with spontaneous portosystemic shunts: effects on parenchymal hepatic enhancement at dual-phase helical CT. Abdominal imaging 2002; 27: 536-540

2 Vignaux 0 , Legmann $P$, Coste J et al. Cirrhotic liver enhancement on dual-phase helical CT: comparison with noncirrhotic livers in $146 \mathrm{pa}-$ tients. Am J Roentgenol American journal of roentgenology 1999; 173: $1193-1197$

3 Garcia P, Genin G, Bret PM et al. Hepatic CT enhancement: effect of the rate and volume of contrast medium injection in an animal model. Abdominal imaging 1999; 24: 597-603

4 Rengo M, Bellini D, De Cecco CN et al. The optimal contrast media policy in CT of the liver. Part I: Technical notes. Acta radiologica 2011; 52: $467-472$

$5 \mathrm{Yu}$ L, Leng S, McCollough CH. Dual-energy CT-based monochromatic imaging. Am J Roentgenol American journal of roentgenology 2012; 199: S9-S15

6 Lewis M, Reid K, Toms AP. Reducing the effects of metal artefact using high keV monoenergetic reconstruction of dual energy CT (DECT) in hip replacements. Skeletal radiology 2013; 42: 275-282

7 Tanaka R, Hayashi T, Ike $M$ et al. Reduction of dark-band-like metal artifacts caused by dental implant bodies using hypothetical monoenergetic imaging after dual-energy computed tomography. Oral surgery, oral medicine, oral pathology and oral radiology 2013; 115: 833-838

8 Guggenberger R, Winklhofer S, Osterhoff G et al. Metallic artefact reduction with monoenergetic dual-energy CT: systematic ex vivo evaluation of posterior spinal fusion implants from various vendors and different spine levels. European radiology 2012; 22: 2357-2364
9 Lee YH, Park KK, Song HT et al. Metal artefact reduction in gemstone spectral imaging dual-energy $\mathrm{CT}$ with and without metal artefact reduction software. European radiology 2012; 22: 1331 - 1340

10 Bamberg F, Dierks A, Nikolaou $K$ et al. Metal artifact reduction by dual energy computed tomography using monoenergetic extrapolation. European radiology 2011; 21: $1424-1429$

11 Zhou C, Zhao YE, Luo S et al. Monoenergetic imaging of dual-energy CT reduces artifacts from implanted metal orthopedic devices in patients with factures. Academic radiology 2011; 18: 1252-1257

12 Venema $H W$. Virtual monochromatic spectral imaging with fast kilovoltage switching should not be used as standard CT imaging modality. Radiology 2011; 260: 916 -917 author reply 917

13 Yu L, Christner JA, Leng S et al. Virtual monochromatic imaging in dualsource dual-energy CT: radiation dose and image quality. Medical physics 2011; 38: $6371-6379$

14 Yuan R, Shuman WP, Earls JP et al. Reduced iodine load at CT pulmonary angiography with dual-energy monochromatic imaging: comparison with standard CT pulmonary angiography-a prospective randomized trial. Radiology 2012; 262: 290-297

15 Apfaltrer $P$ et al. Value of monoenergetic low-kV dual energy CT datasets for improved image quality of CT pulmonary angiography. European journal of radiology (2013), European journal of radiology 2014; 83: $322-330$

16 Cui Y, Gao SY, Wang ZL et al. Which should be the routine crosssectional reconstruction mode in spectral CT imaging: monochromatic or polychromatic? The British journal of radiology 2012; 85: e887e890

17 Lv P, Lin XZ, Chen K et al. Spectral CT in patients with small HCC: investigation of image quality and diagnostic accuracy. European radiology 2012; 22: $2117-2124$

18 Moos SI, van Vemde DN, Stoker J et al. Contrast induced nephropathy in patients undergoing intravenous (IV) contrast enhanced computed tomography (CECT) and the relationship with risk factors: a meta-analysis. European journal of radiology 2013; 82: e387-e399

19 Davenport MS, Khalatbari S, Cohan RH et al. Contrast material-induced nephrotoxicity and intravenous low-osmolality iodinated contrast material: risk stratification by using estimated glomerular filtration rate. Radiology 2013; 268: 719-728 